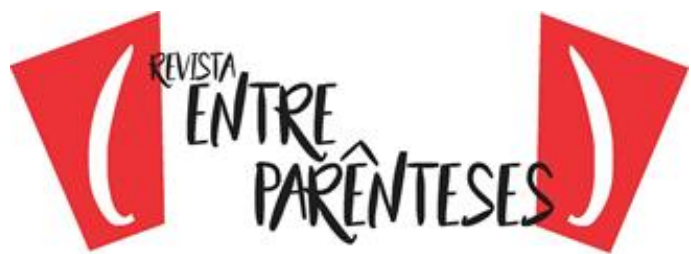

\section{EMPRÉSTIMO LINGUÍSTICO NA LIBRAS: LEMATIZAÇÃO DE SINAIS PURAMENTE DATILOLÓGICOS NO DICIONÁRIO NOVO DEIT-LIBRAS}

\author{
Leandro Andrade FERNANDES ${ }^{1}$ \\ Universidade Federal de Uberlândia - UFU \\ (leandroandrade.letras@gmail.com)
}

\begin{abstract}
Resumo: Admitindo a grande influência que as línguas exercem entre si, a presente investigação objetiva apresentar os empréstimos linguísticos dicionarizados localizados na periferia do léxico da Língua Brasileira de Sinais (Libras), servindo-nos assim de teóricos da lexicologia com ênfase na lexicografia das línguas orais (LO) e das Línguas de Sinais (LS). Utilizamos como fonte para a coleta de dados o Novo DEIT-Libras (2013), contendo este o maior acervo lexical da Libras. Ao analisar os termos aqui apresentados, foi possível verificar a lematização de unidades linguísticas puramente datilológicas, ou seja, a normatização de sinais construídos a partir da soletração manual, recurso que tem como base o alfabeto da Língua Portuguesa (LP).
\end{abstract}

Palavras-chave: Empréstimos linguísticos; Libras; Língua Portuguesa.

Abstract: Assuming the great influence that languages have on each other, the present research aims to present the language dictionaries loans located in the periphery of the lexicon of the Brazilian Sign Language (Libras), thus serving as theorists of lexicology with emphasis on the lexicography of oral languages (OL) and Sign Language (SL). We used as source for data collection the New DEIT-Libras (2013), containing this the largest lexical collection of Libras. By analyzing the terms presented here, it was possible to verify the lemmatization of purely linguistic units, that is, the standardization of signs constructed from manual spelling, which is based on the Portuguese Language (PL) alphabet.

Keywords: Linguistic loans; Libras; Portuguese language.

Resumen: Reconociendo la gran influencia que las lenguas ejercen entre sí, la presente investigación busca presentar los préstamos lingüísticos diccionarizados y localizados en La periferia del léxico de la Lengua Brasileña de Signos (Libras), sirviéndonos para tal fin de teóricos de la lexicología con énfasis en la lexicografía de las lenguas orales (LO) y de lãs lenguas de signos (LS). Utilizamos como fuente para la recolección de datos el Nuevo DEITLibras (2013), poseedor del mayor acervo lexical de la Lengua de Signos. Al analizar estos términos, fue posible verificar la lematización de unidades lingüísticas puramente dactilológicas, o sea, la normativización de señales construidas a partir del deletreado manual, recurso que tiene como base el alfabeto de la lengua Portuguesa (LP).

Palabras Clave: Préstamos lingüísticos; Lengua de Signos; Lengua Portuguesa.

\footnotetext{
${ }^{1}$ Mestre em Estudos da Linguagem pela Universidade Federal de Goiás - UFG/Regional Catalão (2018), licenciado em Letras: Libras pela Universidade Federal de Goiás (2014) e professor assistente de Libras na Universidade Federal de Uberlândia campus Pontal - UFU/Pontal. E-mail: leandroandrade.letras@gmail.com.
} 


\section{("ifirer}

\section{INTRODUÇÃO}

A Língua Brasileira de Sinais (Libras), foi reconhecida pela lei de № 10.436/02 e regulamentada pelo decreto $\mathrm{n}^{0} 5.626 / 05$ como língua oficial da comunidade surda do Brasil. Convive diariamente com a Língua Portuguesa (LP), a língua oral do referido país, dividindo com esta o mesmo espaço geográfico. Tal como as línguas orais (LO), a Libras é composta por um conjunto de regras fonéticas, fonológicas, morfológicas, sintáticas, semânticas e pragmáticas que regem o seu acervo lexical. Conforme Basílio (2004, p. 9), "o léxico é uma espécie de banco de dados previamente classificados, um depósito de elementos de designação, o qual fornece unidades básicas para a construção dos enunciados". A Libras tem seu acervo linguístico próprio, tal como as demais LO e de sinais e realiza constantemente a aquisição de novas palavras oriundas de outras línguas, processo este denominado como empréstimo linguístico.

O processo que dá origem ao empréstimo pode ocorrer de diferentes maneiras, desde dentro da própria língua, atribuindo novos significados a uma lexia, como de outras línguas. Este trabalho objetiva analisar os empréstimos presentes na Libras, provenientes da LP. Por entender a importância dos dicionários em uma comunidade, tomamos este objeto como instrumento para a coleta de dados, utilizando o Novo DEIT-Libras, de Capovilla, Raphael e Mauricio (2013). Assim, compartilhamos a ideia de que as

[...] palavras da língua são aquelas que aparecem listadas nos dicionários. Isso é menos simples do que parece, na medida em que os dicionários sendo responsáveis pelo registro das ocorrências que permanecem na língua, só podem efetuar este registro muito tempo depois de as palavras estarem sendo usadas [...] (BASÍLIO, 2004, p. 13).

O dicionário possui o intuito de representar o léxico de uma língua, estabelecendo, assim, a forma de registrar o lexema na sua modalidade escrita. Desse modo, ele apresenta as palavras que pertencem à língua, distinguindo-as das que não pertencem ao acervo lexical da língua-alvo. No entanto, conforme Biderman 


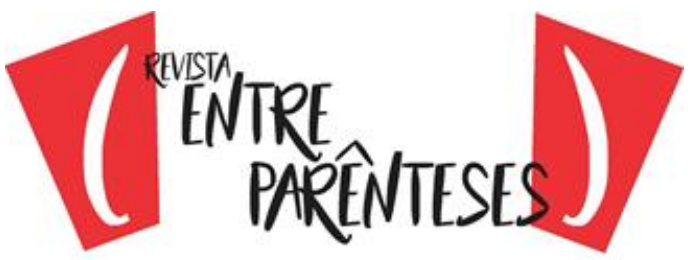

(2001), é importante ressaltar que o dicionário não consegue registrar todo o léxico de uma língua, podendo ocorrer a presença de determinadas unidades lexicais em alguns dicionários e sua ausência em outros. De forma a favorecer significativamente esta investigação, servimo-nos do dicionário, e assim foram selecionadas as lexias a serem evidenciadas nesta pesquisa e, consequentemente, nosso corpus de exclusão.

A Libras realiza constantemente empréstimos da LP, por ser esta a língua de maior contato com aquela; por este motivo, acredita-se que os empréstimos da LP pela Libras ocorrem de forma direta, pois, não passam por outra língua antes de ser incorporada à Libras, termo este apresentado por Carvalho (1989). Por este motivo, tenciona-se inventariar os empréstimos linguísticos dicionarizados na Libras, levando em consideração os lexemas arrolados no Novo DEIT-Libras (2013).

\section{DELIMITAÇÃO DOS CONCEITOS DE EMPRÉSTIMO E ESTRANGEIRISMO}

Nesta primeira parte, objetivamos diferenciar empréstimos de estrangeirismos, dois termos que podem ter concepções diferentes, conforme referencial utilizado em uma pesquisa. Para Zilles e Garcez (2006, p. 15), "estrangeirismo é o emprego, na língua de uma comunidade, de elementos oriundos de outras línguas", ou seja, são expressões de diferentes línguas adicionadas a uma língua-alvo. Conquanto, estes mesmos autores complementam este conceito com a afirmação de que os estrangeirismos são palavras que conservam sua identidade alienígena em sua grafia, isto é, não se moldando à língua-alvo.

Gonçalves, Ferreira e Cunha (2011), diferenciam de forma clara estes dois conceitos, como pode ser observado a seguir:

Em primeiro lugar, temos o estrangeirismo, que vem a ser 0 emprego de palavras que se originam de outra língua estrangeira e não possuem uma palavra correspondente a ela na nossa língua, apontadas em nossas normas gramaticais como um vício de linguagem, e que sua pronúncia e escrita não sofre qualquer alteração. No segundo caso o empréstimo (galicismo, anglicismo, etc.), a própria nomenclatura deixa clara a função das palavras, que sofre pouca modificação e passa a fazer parte do léxico, sendo que 


\section{("ting}

todas elas hoje classificadas como empréstimo foi um dia estrangeirismo (GONÇALVES; FERREIRA; CUNHA, 2011, p. 2-4 apud TIMBANE, 2012, p. 291, grifo do autor).

Como demonstra o excerto acima, Gonçalves, Ferreira e Cunha (2011) apud Timbane (2012, p. 291), defendem a ideia de estrangeirismos como termos advindos de outras línguas, que ao serem adicionados à língua-alvo não sofrem alterações gráficas, permanecendo com seu caráter alienígena, por exemplo, "online", lexia da língua inglesa presente na LP. Podemos assemelhar esta visão com o conceito de Zilles e Garcez (2006), termos adquiridos de outras línguas permanecendo estranha a língua exportadora. Empréstimos seriam, nesta concepção, os lexemas oriundos de outras línguas que sofreram alterações ao serem incorporados à língua-alvo.

No entanto, o conceito que nos parece mais adequado, levado por nós em consideração, é o de Alves (2007, p. 72): "numa primeira etapa, o elemento estrangeiro, empregado em outro sistema linguístico, é sentido como exterior ao vernáculo dessa língua. É então denominado estrangeirismo, ou seja, ainda não faz parte do acervo lexical". E reforçamos com Carvalho (1989, p. 44), ao afirmar que: "um termo estrangeiro perde esta condição quando não é mais percebido como tal. Se ele permanece escrito na sua forma de origem, será sempre sentido como estranho ao sistema linguístico, quanto à sua forma escrita, o seu visual". Neste sentido, tomaremos como estrangeirismos as lexias que são utilizadas socialmente, no entanto, não foram de alguma forma dicionarizadas, não possuem uma "certidão de nascimento".

Os empréstimos serão aqui entendidos como lexemas adquiridos de outras línguas, que ao serem incorporados na língua alvo, ou seja, dicionarizados, em um sistema de escrita, sofrem alguma adaptação, conforme apresentado por Carvalho (1989, p. 37): "a tendência dos empréstimos é adotar a fisionomia morfológica e fonológica da língua importadora", por exemplo, o lexema "shampoo" da língua inglesa, que ao ser incorporado ao léxico da LP também é registrado como "xampu". Portanto, reconhecemos como estrangeirismos as palavras advindas de outras línguas que ainda não foram dicionarizadas na língua-alvo, como a palavra "crush", ainda não incluída graficamente na LP. Não obstante, empréstimos serão aquelas 


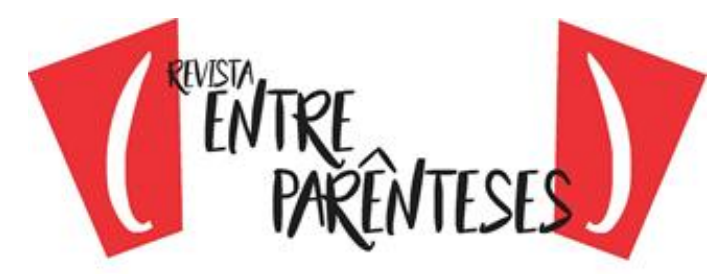

palavras já incorporadas à língua, dicionarizadas, e que sofreram alguma alteração, como apresentado pela autora supracitada:

O emprego frequente de um estrangeirismo constitui também um critério para que essa forma estrangeira seja considerada parte do componente do acervo lexical português. Jeans, unidade lexical tão usada contemporaneamente, parece-nos já adaptada à língua portuguesa e manifesta-se, por isso, como um empréstimo ao nosso idioma (ALVES, 2007, p. 79).

Isto posto, entendemos que palavras como "deletar, toalete e futebol" perderam a característica de estrangeirismos, por sofrerem alterações gráficas e por serem incluídas no acervo lexical da LP, difundidas socialmente, tornando-se empréstimos. Reforça Carvalho (1989, p. 43) que, "utilizando a dicotomia saussuriana langue/parole, enquanto o estrangeirismo faz parte da parole - uso individual, o empréstimo passa a ser um elemento da langue, já socializado". A referida autora faz outra diferenciação entre as novas lexias da língua, separando aquelas que sofreram alteração gráfica, designadas de empréstimos, daquelas que permanecem com sua escrita genuína, denominando-as de xenismos: por exemplo, “Wifi", "Windows" e "software", pertencentes à língua inglesa e já dicionarizadas na LP na forma gráfica da língua exportadora.

As línguas estão em constante modificação, seja por ela mesma, com mudanças diacrônicas, ou pelo contato com outras línguas, fenômeno intrínseco a elas. Por ser um fato que ocorre inicialmente na língua falada, denominado aqui de estrangeirismo, não pode ser controlado, ou seja, cada um fala e utiliza a língua de forma individual, ao passo que é concretizada pela grafia, tornando-se parte do acervo lexical, designando de empréstimos aqueles que sofrem alguma modificação e xenismos os que permanecem com a escrita da língua de origem. Como visto, há algumas discordâncias sobre o conceito e uso destes termos, contudo, alude este fenômeno, à aquisição de palavras de uma língua fonte por uma língua-alvo, fato aceito por todos os autores aqui abordados. 


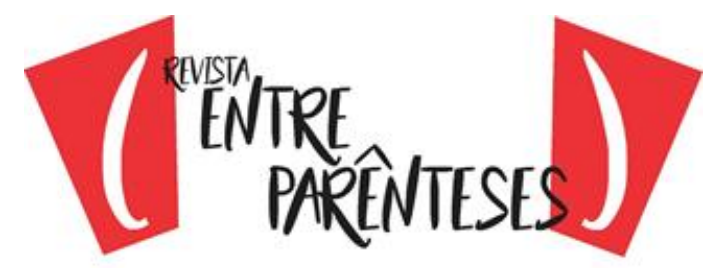

\section{PROCESSO DE EMPRÉSTIMO LINGUíSTICO NA LIBRAS}

Em sua maioria, os trabalhos referentes a empréstimos na Libras são provenientes de estudos relacionados a aquisições lexicais da LP, por meio de um artifício próprio das LS, denominado de datilologia ou soletração manual. A datilologia:

[...] pode ser comparada à soletração em línguas orais. Faz-se a comparação a correspondência de uma letra da grafia de uma língua oral com uma configuração de mão $(\mathrm{CM})$ de uma língua de sinais, às vezes acrescida de movimentos, como ocorre na $\mathrm{LSB}^{2}$ com as CMs Ç, H, J, K, X, Y e Z (NASCIMENTO, 2010, p. 27).

A datilologia representa 0 alfabeto gráfico das LO, nutrindo cada LS sua própria tabela de alfabeto manual. A seguir apresentamos o alfabeto manual da Libras:

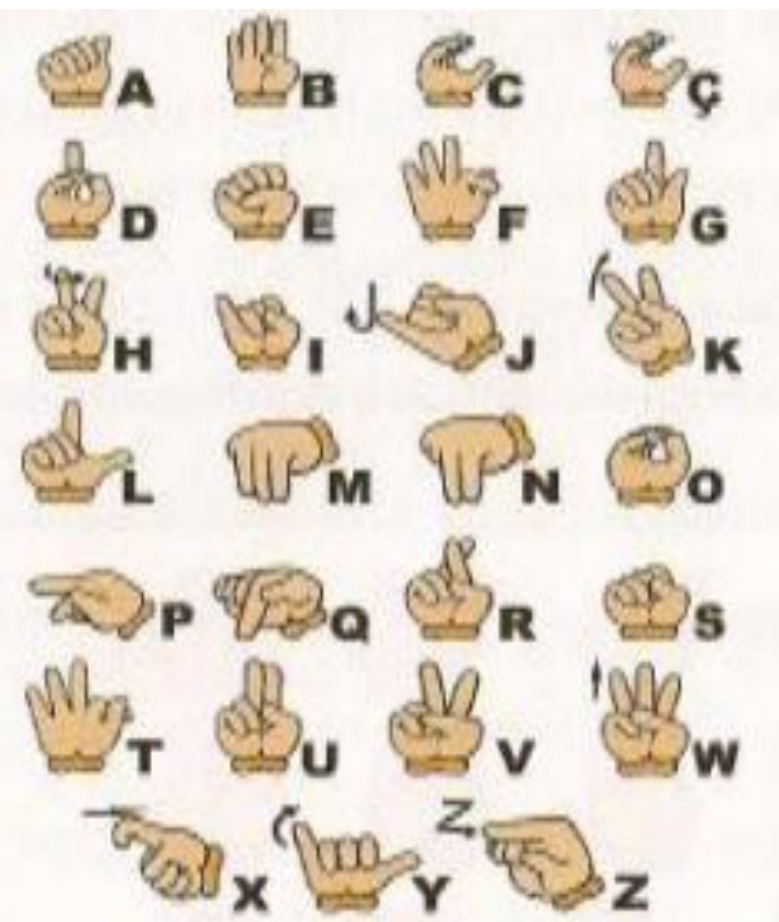

Fonte: Alfabeto datilológico da Libras, por Quadros e Pimenta (2006, p. 64).

\footnotetext{
${ }^{2} \mathrm{~A}$ sigla LSB, nesse contexto, refere-se à Língua de Sinais Brasileira.
} 


\section{("titrer}

Como mencionado, em sua maioria, os estudos referentes a empréstimos nas LS são relacionados à datilologia, como revelam Battison (1978) e Bellugi (1981), sobre as Línguas Americanas de Sinais (ASL), Mineiro e Duarte (2007), na Língua Gestual Portuguesa (LGP), e Quadros e Karnopp (2004) e Ferreira-Brito (1995), na Libras. Os referidos autores estabeleceram uma taxonomia própria para o estudo destes empréstimos. Segundo eles, os empréstimos se tornam semelhantes ao sistema-alvo, desta forma condiz aqui diferenciar a datilologia do empréstimo linguístico.

De acordo com Nascimento (2010, p. 32), a datilologia é um processo que pode ser realizado para suprir uma lacuna em um determinado momento no processo de comunicação, não se incorporando ao léxico. Por exemplo, a palavra "querer" possui um sinal na Libras, "<า $\boxminus \square T^{3 "}$ ", no entanto, durante a comunicação, o interlocutor pode utilizar a datilologia, substituindo assim este sinal, o que parece ser momentâneo. Já o empréstimo por meio da datilologia é incorporado ao sistema, dispondo da aparência da língua alvo, como o sinal de "março", que é realizado pela

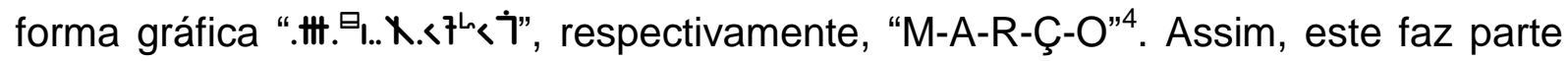
do acervo lexical, não havendo outro modo de referir-se a este termo ${ }^{5}$.

Observa-se, pois, que a aquisição de novas palavras da LP para a Libras ocorre de forma mais frequente do que as que advêm de outras LS ou LO. Esta maior frequência ocorre pelo fato de conviverem em um mesmo espaço, conforme elucidam as autoras:

[...] na $\mathrm{LSB}^{6}$, o Inglês é a língua com maior número de doação, não outras línguas de sinais. Isso ocorre porque todas as línguas realizam empréstimos principalmente da língua com a qual mantêm maior contato. Os sinalizantes (ou usuários de sinais) britânicos têm

\footnotetext{
${ }^{3}$ Para elucidar o referente na Libras, neste trabalho será utilizada a ELiS - Sistema Brasileiro de Escrita das Língua de Sinais desenvolvida por Barros (2015).

${ }^{4}$ Há um consenso de que palavras soletradas, ou seja, que utilizem o recurso da datilologia, ao serem traduzidas para outra língua, em nosso caso a LP, têm as letras separadas por "-".

${ }^{5}$ Atualmente, é possível perceber em alguns estados do Brasil um sinal distinto para o lexema março, no entanto, em Goiânia, de modo geral, o sinal utilizado é o soletrado, não dispondo de um sinal próprio para o mesmo.

${ }^{6}$ A sigla LSB, nesse contexto, refere-se à Língua de Sinais Britânica.
} 


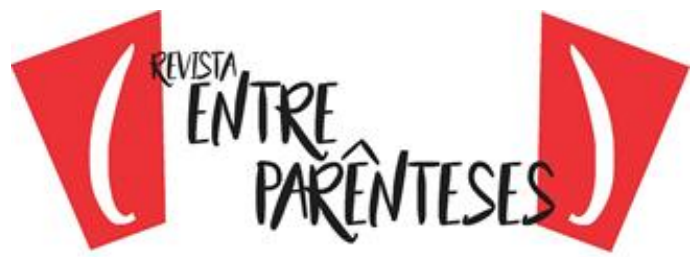

mais contato com o inglês, portanto adquirem mais empréstimos do inglês (SPENSE; WOLL, 1999, p. 216 apud NASCIMENTO, 2010, p. 30).

A presente pesquisa possui o objetivo de evidenciar os empréstimos linguísticos realizados entre a Libras e a LP. Na passagem para a Libras, estas unidades lexicais sofrem uma modificação fonológica, já que estas línguas possuem diferentes modalidades, esta é espaço-visual e a LP oral-auditiva. Ocorre assim uma adaptação destas lexias, passando da modalidade escrita de uma língua para a modalidade visual de outra.

Nascimento (2009, p. 60-70), expõe uma taxonomia para a organização dos empréstimos na Libras, dispondo como referência das propostas de Battison (1978) e Bellugi (1981) em ASL, Mineiro e Duarte (2007) em LGP e dos estudos para a Libras de Quadros e Karnopp (2004) e Ferreira-Brito (1995). Em sua pesquisa, expõe, entre outros, os empréstimos datilológicos por transliteração.

Os empréstimos por transliterações lexicalizadas são definidos por Nascimento (2009, p. 65), como sinais parcialmente datilológicos ou abreviados. No entanto, este pode ou não sofrer modificações, ocorrendo assim, mudanças morfológicas no sinal. Esta conversão objetiva atribuir à lexia exportada as mesmas características da língua importadora. Desta forma, estas unidades linguísticas podem manifestar: a letra inicial coadunada à mudança do Ponto de Articulação (PA), o acréscimo de Movimento ( $M)$; a supressão de letras ou sua abreviação.

Nesta pesquisa, será realizada a investigação dos empréstimos por transliterações lexicalizadas puramente datilológicas, ou seja, sinais dicionarizados que utilizem apenas o alfabeto manual e que este seja para a representação total de um lexema da LP na Libras.

Ainda sobre os sinais datilológicos, Quadros e Karnopp (2004), elucidam a estrutura do léxico da Libras, nesta ocasião, apresentam os sinais datilológicos como lexemas não-nativos, como pode ser observado a seguir: 


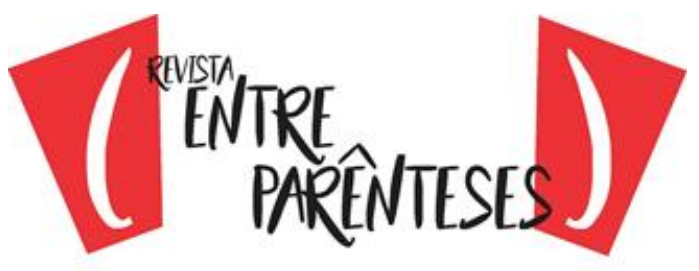

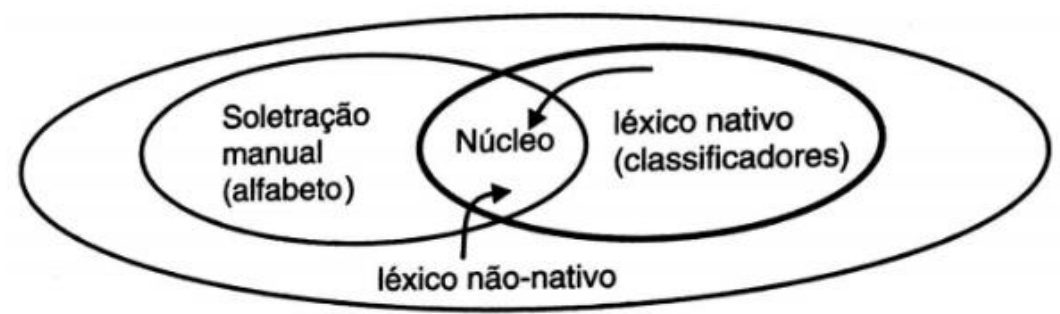

Fonte: Estrutura do léxico das LS, Brentari e Padden, 2001, apud Quadros e Karnopp 2004

Conforme imagem anterior, a soletração manual, ou seja, os sinais puramente datilológicos podem ser considerados lexias pertencentes à periferia do léxico das línguas de sinais. Esta teoria se justifica por serem estes elementos representações do alfabeto da LP, não apresentam elementos linguísticos intrínsecos ao léxico das LS. Como é sabido, os elementos fonológicos das línguas de sinais se referem aos cinco parâmetros, sendo eles a configuração de mão (CM), orientação da palma $(\mathrm{OP})$, ponto de articulação (PA), movimento (M) e expressões não manuais (ENM). Em sinais datilológicos, sua estrutura manifesta unicamente o parâmetro $\mathrm{CM}$, por este motivo, não são reconhecidos como sinais nativos, mas empréstimos.

\section{ANÁLISE DE DADOS}

O corpus da presente pesquisa foi retirado do dicionário Novo DEIT-Libras (2013), que comporta a maior quantidade de vocábulos da Libras, sendo este também o mais utilizado pela comunidade surda. Organizado por Capovilla, Raphael e Mauricio, a obra utilizada é a terceira edição ${ }^{7}$ e teve como base a linguística e a neurociência cognitiva para a sua construção. O dicionário se divide em dois volumes, organizados de forma alfabética, obedecendo à estrutura da LP.

Foram analisados os dois volumes do dicionário Novo DEIT-Libras (2013), objetivando selecionar os vocábulos que se enquadrassem na categoria de empréstimos transliterados. A concepção aqui assumida é a apresentada por Carvalho (1989), que define empréstimos como lexias advindas de outras línguas

\footnotetext{
${ }^{7}$ Atualmente há uma quarta edição do dicionário, intitulado "Dicionário da Língua de Sinais do Brasil: a libras em suas mãos". No entanto, no momento da coleta de dados o mesmo não havia sido publicado.
} 


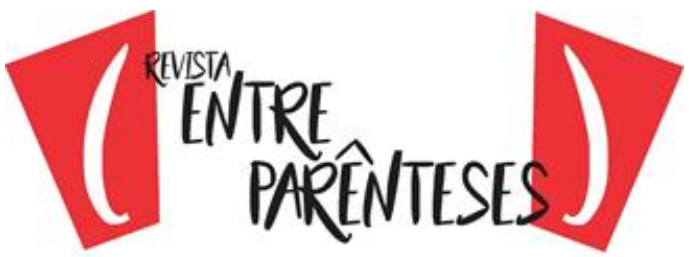

que, ao serem dicionarizados, podem sofrer alguma modificação, sendo ela morfológica ou fonológica.

Após a seleção dos lexemas por transliteração lexicalizados, realizamos uma segunda apuração, tendo esta o objetivo de separar aqueles que são sinais puramente datilológicos daqueles que são por abreviação ou híbridos. Isto posto, organizamos os dados aqui a serem apresentados e analisados. Para a representação dos dados na Libras, recorremos ao sistema de Escrita das línguas de Sinais - ELiS. A ELiS foi criada por Barros (1998), sua estrutura representa os cinco parâmetros das LS, já mencionados anteriormente. Porém, com o objetivo simplificar a escrita, sua criadora alterou o parâmetro CM para Configuração de dedos (CD) e uniu os dois último em um único grupo, denominado apenas de Movimento.

Destarte, a estrutura base da ELiS corresponde a Configuração de mão, Orientação da palma, Ponto articulação e Movimento - CD, OP, PA, M. como pode ser observado no sinal amarelo "<li四므", <li refere-se a CD, س refere-se a OP, 므 refere-se ao PA e $\downarrow$ refere-se ao M. A presente pesquisa tem como objetivo a análise de empréstimos linguísticos, entre estes, unicamente os por transliteração lexicalizada, portanto, o único grupo a estar presente será o de $C D$, uma vez que as lexias selecionadas são representadas pelo alfabeto datilológico.

Finalizada a distinção dos dados coletados e sua escrita em ELiS, foram totalizados cento e vinte e três (123) sinais transliterados puramente datilológicos. Entre estes, quatorze (14) nomes próprios e 109 comuns. Após a apresentação dos dados, serão discutidas as ponderações julgadas importantes para esta pesquisa.

Tabela 1: Empréstimos linguísticos por transliteração lexicalizada com base no Novo DEIT-Libras (2013).

\begin{tabular}{|c|c|}
\hline \multicolumn{2}{|l|}{ SOLETRADOS } \\
\hline LP & ELiS \\
\hline Alho & 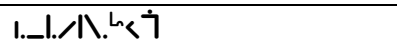 \\
\hline Ano (data de fabricação) & 1..tt. $\ominus_{<}>7$ \\
\hline $\mathrm{Ar}$ & $1 . . x$. \\
\hline $\begin{array}{l}\text { Assistência médica internacional LTDA - AMIL (plano de } \\
\text { saúde) }\end{array}$ & I...tt. $.^{\ominus} . .$. I_l. \\
\hline Ator & I. 八kं. X. \\
\hline Atriz & $1 .>I . X \ldots . . . . .1 I^{\perp \oplus}$ \\
\hline Autônomo (a) & 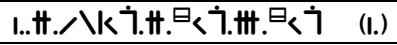 \\
\hline
\end{tabular}




\section{("ivitive

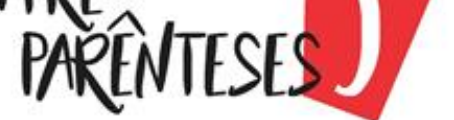

\begin{tabular}{|c|c|}
\hline Autor (autora) & 1..t.八Kخ.X.(1.) \\
\hline Avenida (endereço) & 1..ll. \\
\hline Azar & 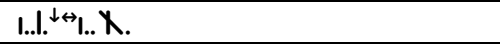 \\
\hline Babá & /tı./t. \\
\hline Bairro barris (Salvador, BA) & $>+1 . . \times \ldots . . . . . .10$ \\
\hline Bairro graça (Salvador, BA) & 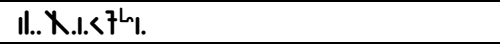 \\
\hline Bairro luz (São Paulo, SP) & $-1 . . t$.I. ${ }^{\downarrow \leftrightarrow}$ \\
\hline Bar & t+...X. \\
\hline Baú & ti..t. \\
\hline Berinjela & /t<7.X.......tt. $. . . .10<7 \_l . .1$. \\
\hline Bico (trabalho) & d十...kł<j \\
\hline Boletim de ocorrência (BO) & 八大う \\
\hline Cadastro de pessoa física (CPF) & 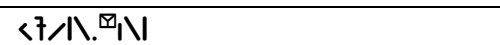 \\
\hline Cartão de identificação do contribuinte & $<7 . . . k 7$ \\
\hline Chevrolet & $<7 ハ ハ .\left\llcorner<7.11 . . \times .<7 \_1 .<7 ハ\right.$ \\
\hline Classificador (CL) & $\left\langle 7 \_I\right.$. \\
\hline Código de endereçamento postal (CEP) & くネくフハハ. \\
\hline Confederação brasileira desportiva de surdos (CBDS) & 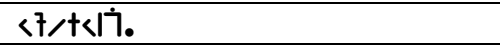 \\
\hline $\begin{array}{l}\text { Conselho nacional de desenvolvimento científico e tecnológico } \\
\text { (CNPQ) }\end{array}$ & 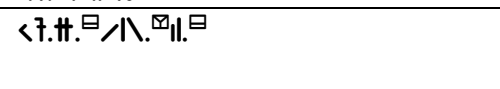 \\
\hline Consolidação das leis do trabalho (CLT) & $\left\langle\boldsymbol{Z F}_{-} \mathrm{I} . \lambda \mathrm{I}\right.$ \\
\hline $\begin{array}{l}\text { Coordenadoria de aperfeiçoamento de pessoal de nível superior } \\
\text { (CAPES) }\end{array}$ & $<7 ı . ハ . \otimes / 7$. \\
\hline Cor & $<7<7 . x$. \\
\hline Cor rosa & 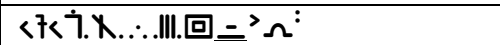 \\
\hline CPU (computador) & くҰハハ. \\
\hline Creme (alimento) & $<7$. X.<7. Ht. ${ }^{\ominus}<7$ \\
\hline Creme para cabelo (condicionador) & $<7 . x .<7 . \mathrm{H} . \theta_{<7}$ \\
\hline Cristão (cristã) (igreja católica) & $<7 . X \ldots . . .1 . 八 \backslash 1 .<7$ \\
\hline Cuba & $<$ f.tt./tı. \\
\hline Data & $\langle i 7 . . .1 . .1$. \\
\hline Declaração (documento) & 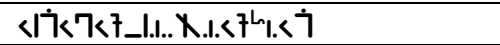 \\
\hline Departamento & 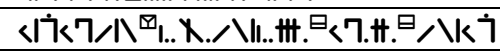 \\
\hline Dia (data) & \langle\rangle$\overline{l . . .1 .}$ \\
\hline DOC (informática, documento em word) & $<1 \bar{k} \dot{k} 7$ \\
\hline Dvd & $<17 . \mid l .<17$ \\
\hline Edição & $<7<17 \ldots . . . k 7^{h} .<7$ \\
\hline Ensino de pós-graduação & ハ.『う. \\
\hline Ética & $<7$ 八I....kłı. \\
\hline Excel (informática) & <7.7. ¿_.।. \\
\hline Fábrica italiana de automóveis torino (FIAT) & N\....II.八I \\
\hline Fax & N11..7. ${ }^{\downarrow}$ \\
\hline Fé & INk 7 \\
\hline Fim & "IINI...I..tI. ${ }^{\boxminus}$ \\
\hline Federação mundial dos surdos (FMS) & NI.H..$^{\ominus}$ \\
\hline Ford & IN7.X.<i \\
\hline $\begin{array}{l}\text { Fundação de amparo à pesquisa do estado de São Paulo } \\
\text { (FAPESP) }\end{array}$ & 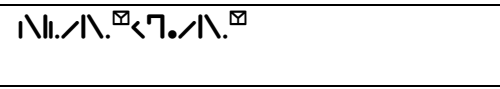 \\
\hline Fundação estadual para o bem-estar do menor (FEBEM) & 1Nk7/く7.\#. \\
\hline Gás & H.I.. \\
\hline Gay & $\mid 1.1 . . . . . I^{L}$ \\
\hline Gel & I.<7_I. \\
\hline Goiás (estado brasileiro) & 11.<7....1.. \\
\hline
\end{tabular}




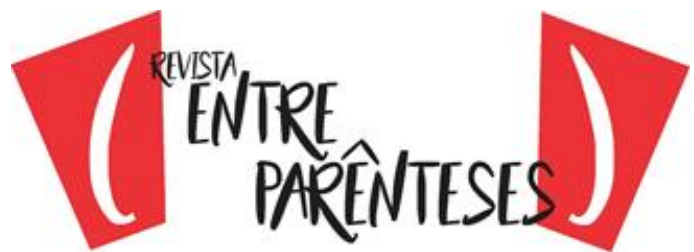

\begin{tabular}{|c|c|}
\hline Gonorreia & 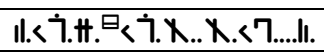 \\
\hline Grau (série escolar) & II.X.I..tt. \\
\hline HTML (informática) & 八. \\
\hline ICQ (informática) & ....k Fil.. \\
\hline Ilegal & ....I_I.< 7il.I._I. \\
\hline Jauá (praia de BA) & .... L ${ }^{\circ} \ldots .$. H.I. \\
\hline Java (informática) & 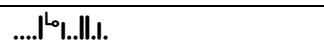 \\
\hline Lã & -l..1. \\
\hline Lesão por esforço repetitivo (LER) & -I.<7.X. \\
\hline Leste (orientação geográfica) & -l.<7.八k7 \\
\hline Líder & _l....kiخ $7 . x$. \\
\hline Lixo (material descartado) & -1.......7. ${ }^{\downarrow}<7$ \\
\hline Loto, loteria & 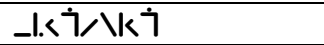 \\
\hline Maio & . $\mathrm{m} . \ominus_{1 . . . . . k j}$ \\
\hline Março & 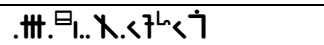 \\
\hline $\mathrm{Mel}$ & . HI. ${ }^{\theta}<7 \_I$. \\
\hline Merda (expressão vulgar) & 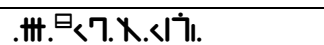 \\
\hline Mestrado & 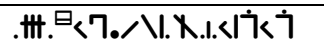 \\
\hline Mil & 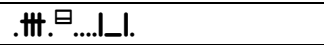 \\
\hline Miopia & 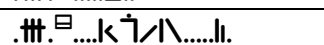 \\
\hline Moça & 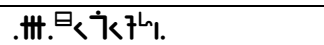 \\
\hline Mofo, mofado (a) & 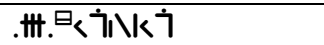 \\
\hline Msn (Microsoft service network) (informática) & . \\
\hline Mula & 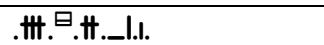 \\
\hline Nabo & $. \# .^{I_{1} / t<>7}$ \\
\hline Norte (orientação geográfica) & 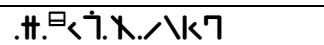 \\
\hline Nunca & 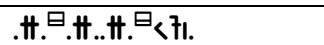 \\
\hline Ódio & 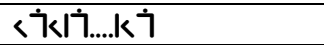 \\
\hline Oeste (orientação geográfica) & $<7<7 . 八 \mathrm{k} 7$ \\
\hline Oi (saudação) & $\langle 7 \ldots . . .1$ \\
\hline Oi (operadora de telefonia) & $<7 \ldots . . .1$ \\
\hline Ok! (okay! Tudo bem! Tudo certo!) & <オハ. ${ }^{\uparrow}$ \\
\hline $\mathrm{Ou}$ & $<$ خ.t. \\
\hline Paz & 八ハ..$_{1 . . . .^{\downarrow \leftrightarrow}}{ }^{\dagger}$ \\
\hline Pé & 八. $\otimes_{<}>7$ \\
\hline Povo & 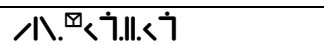 \\
\hline Prazo (tempo) & 八. ${ }^{\square} \times X . . . . I^{\oplus \downarrow}<>$ \\
\hline Pudim & 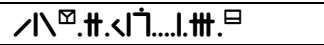 \\
\hline Raça & X.1.<7เ \\
\hline Real (dinheiro) & . X.<7.__l. \\
\hline Saco & $0.1 .<7<7$ \\
\hline Sal & .1._._. \\
\hline Sala & I._l.t. \\
\hline Salgado (a) (que contém sal) & .1._l. \\
\hline Século & 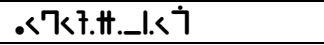 \\
\hline Sede (local) & $.<7<1$ |ं<7 \\
\hline Senador (senadora) & .<7.H. \\
\hline Show & . $\mathbb{1}^{\llcorner}<7.111$. \\
\hline Sífilis & .....IINI....I_I....... \\
\hline Signo (zodíaco) & .....11...t. $\ominus_{<}>\overline{7}$ \\
\hline Sim, sim! & .......世的 \\
\hline Soja &.$<7 . . .1 \%$ \\
\hline Suco & ..tt.<子< \\
\hline
\end{tabular}




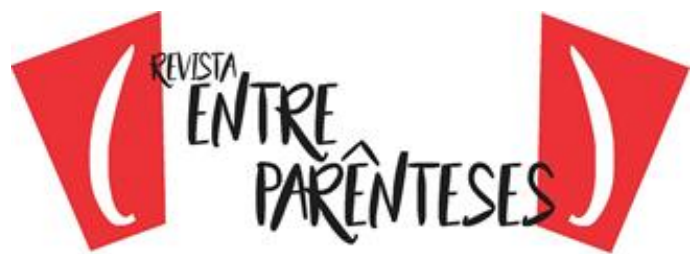

\begin{tabular}{|c|c|}
\hline Sul (orientação geográfica) & o.tt._l. \\
\hline Sistema único de saúde (SUS) & ..tt.. \\
\hline Telefone de texto (TDD ou TTY) & 八klïli \\
\hline Tendão & 八k7.t. ${ }^{\bullet}<1$ iı.<7 \\
\hline Tim (operadora de telefonia) & 八I......H. ${ }^{\ominus}$ \\
\hline Urso & .tt..X.०<7 \\
\hline USB (universal serial bus) (informática) & $. t . . / t+$ \\
\hline Unidade terapia intensiva (UTI) & $. \mathrm{H} . 八 \mathrm{~N} . . . \mathrm{I}$ \\
\hline Vaga (estacionar) & II.I.I.l.1. \\
\hline Verso & .11.<7.X.०<7 \\
\hline Vice & $.11 . . . .1<7<7$ \\
\hline Vovô (vovó) & 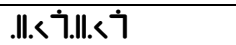 \\
\hline Word (informática) & III.<7.X.<17 \\
\hline
\end{tabular}

Fonte: Elaborado pelo autor.

É pertinente destacar que os sinais híbridos ${ }^{8}$, ou seja, aqueles lexemas que apresentam em sua estrutura a composição de sinal junto a digitação manual, não foram computados em nossa pesquisa, como o verbete "Banco Caixa Econômica

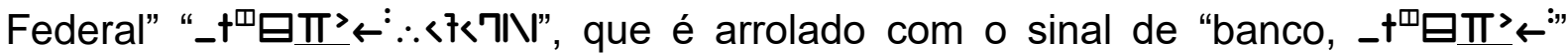
acrescido a digitação das letras "C-E-F, < $7<7 \mathbb{N} \mathrm{N}$ ". Do mesmo modo, não foram inventariadas as lexias reproduzidas em mais de uma entrada, por exemplo, o verbete "SUS" que igualmente é arrolado em uma entrada própria como "Sistema Único de Saúde", com o mesmo sinal datilológico "..tt.o".

Ao observar as entradas no Novo DEIT-Libras (2013), pode-se perceber que algumas lexias são dicionarizadas utilizando o recurso da digitação manual e em outro verbete, o sinal em Libras, ou seja, para alguns lexemas há sua representação em Libras, no entanto, sua forma pelo recurso da datilologia também é registrada. Desta forma, há a duplicação destes verbetes, como na entrada "ética", que possui o equivalente em Libras representado pela datilologia "<7>….k 7ı." e, em outra entrada,

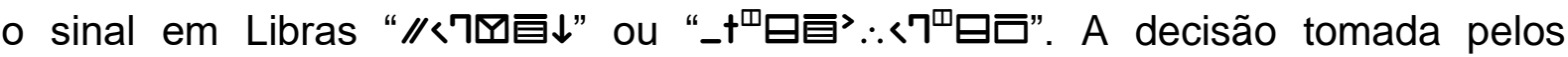
autores do dicionário analisado pode ser justificada pelo fato de que alguns lexemas ainda estão em processo de divulgação, assim, há necessidade de registrar a digitação manual e o sinal já incorporado ao acervo lexical da Libras, bem como a possibilidade da variação do sinal em determinadas regiões, podendo ser utilizada a forma datilológica em um lugar e o sinal em outro.

\footnotetext{
${ }^{8}$ Cunha e Cintra (2001, p. 115$)$, definem hibridismo como "palavras que se formam de elementos
} tirados de línguas diferentes". Em nosso caso, elementos da Libras e da LP. 


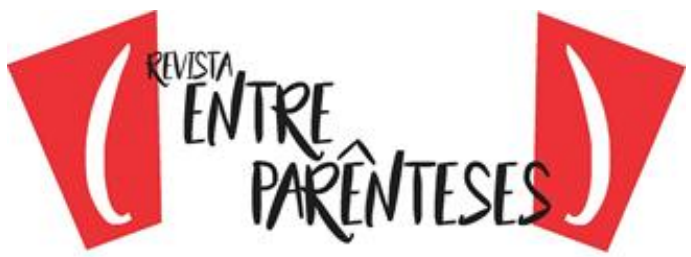

Evidenciamos, desta forma, a variação linguística presente neste dicionário, sendo que, alguns lexemas são arrolados em mais de uma entrada, contendo o mesmo valor semântico e utilizando as mesmas informações em suas microestruturas, com as mesmas ilustrações, exemplos e conceitos. Pode-se exemplificar a duplicação já mencionada de lexemas dicionarizados por extenso e em sua forma abreviada, por sigla ou acrônimo, junto à presença do termo genérico, em verbetes toponímicos, como em "Bairro Luz, _l..t.....$^{\downarrow \star » ”}$, registrado também apenas com o termo específico "Luz, _I..tt.I. ${ }^{\downarrow \star » "}$. Interessante observar que, apesar de haver esta diferença nas entradas em LP, ou seja, o uso o termo genérico "bairro", o equivalente em Libras não é fidedigno à entrada, por não ser apresentado o termo genérico do mesmo, ou seja, em LP há o sintagma "bairro Luz", mas no equivalente em Libras há a exclusão do substantivo "Bairro", permanecendo apenas o substantivo "Luz". Como pode ser observado a seguir:
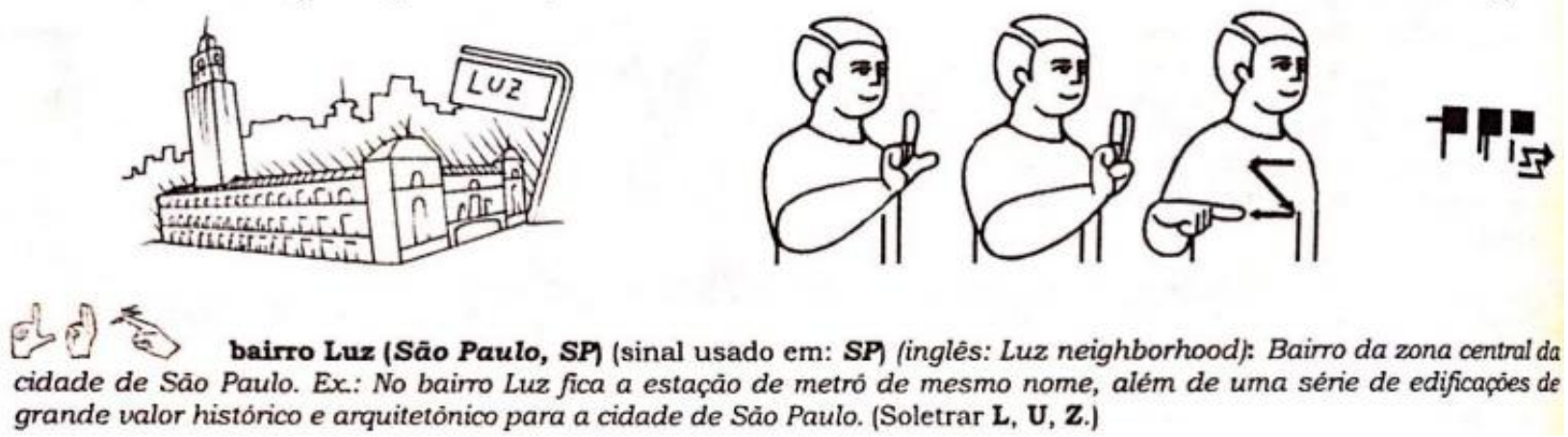
grande valor histórico e arquitetỏnico para a cidade de Sảo Paulo. (Soletrar L, U, Z.)

Fonte: Capovila, Raphael e Mauricio (2013, p. 1609).

As variações linguísticas se fazem presentes em todos os dicionários, de qualquer língua, no entanto, elas são organizadas em dicionários de LO de forma diferente. As lexias que variam, mas que possuem o mesmo valor semântico, são organizadas em uma única entrada, havendo dentro desta as diversas formas gráficas de cada variação e suas marcas de uso. Podemos justificar a peripécia das unidades lexicais serem introduzidas em entradas diferentes, pela circunstância de que o Novo DEIT-Libras não é construído em função da estrutura da Libras, mas sim da LP. No dicionário, é possível perceber a utilização do alfabeto manual, a escrita SignWritting, e ilustrações do modo de sinalização da entrada. No entanto, estes 


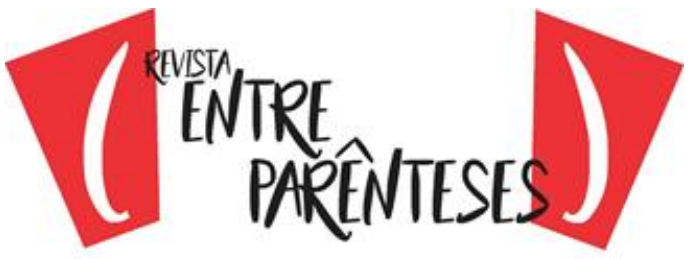

elementos, que são próprios da Libras, estão em segundo plano, sobressaindo assim, a LP.

Por representar a Libras por meio de imagens, o referido dicionário entende ser necessário separar as variantes em diferentes entradas. Para solucionar este entrave, temos o Sistema Brasileiro de Escrita das Línguas de Sinais - ELiS (BARROS, 2015), escrita utilizada para elucidar os sinais em Libras nesta pesquisa. Possibilita a representação da Libras ou de qualquer outra LS na sua forma escrita, assim como a organização das entradas na ordem alfabética das LS, desvinculando a organização dos lexemas em dicionários de LS pela escrita em LP e também da representação do signo linguístico por imagens, ilustrações ou fotos.

A Libras convive em um território em que a língua oficial é oral, ou seja, a LP. Por este motivo, os empréstimos nesta língua são de origem interna, isto é, íntima, e sua forma de derivação é direta, da LP para a Libras. Neste processo, a Libras realiza uma adaptação fonológica por ser de modalidade espaço-visual, diferente das LO, que são orais-auditivas. Portanto, estes empréstimos estão presentes na Libras, seja de forma direta ou indireta, compartilhando assim a ideia de que as línguas realizam contato entre si, independentemente de suas modalidades.

\section{CONSIDERAÇÕES FINAIS}

Dispondo das considerações e análises aqui evidenciadas, salientamos a presença de empréstimos na Libras provenientes da LP de forma direta, ratificando assim, a hipótese inicial deste trabalho, ou seja, o registro de empréstimos linguísticos em dicionários de Libras. No que se refere à estrutura de dicionários, destacamos a diferença entre as estruturas, seleção e disposição dos elementos componentes nos dicionários de LO e no Novo DEIT-Libras (2013), uma vez que neste as variações são inseridas em diferentes entradas. Além de acentuar a dicionarização de empréstimos relativos a um mesmo referente, isto é, apresentando unidades linguísticas com o auxílio da datilologia - empréstimo -, e por sinal construção própria na Libras. 


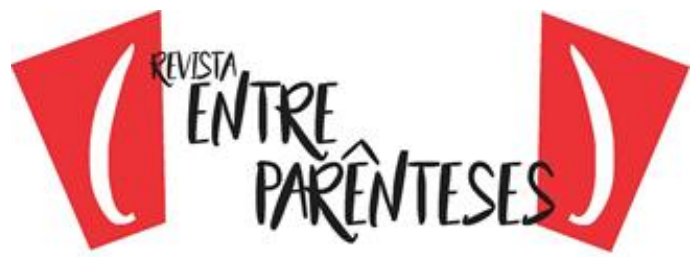

Concerne às línguas à função de possibilitar a comunicação entre membros de uma comunidade e entre estes e o mundo, impossibilitando que a língua seja fechada ao contato com outras línguas e culturas. Isto posto, a Libras realiza contato com outras línguas; a proximidade entre elas ocasiona influências, ocorrendo assim os empréstimos, objeto investigado neste trabalho. É impossível o controle da aquisição de termos oriundos de outras línguas, uma vez que este processo se inicia na língua falada e, posteriormente, é inserido na língua escrita, tornando possível a sua incorporação ao acervo da língua-alvo. Além disso, as interpenetrações linguísticas são comuns em todas as línguas e não há razões para que se defenda o purismo linguístico, como se os empréstimos representassem uma ameaça à autonomia de qualquer língua.

Esta pesquisa levou em consideração os empréstimos linguísticos realizados da LP pela Libras, com o objetivo de verificar sua forma de lexicalização, ou seja, a utilização da digitação manual como registro de lexemas na Libras incorporados ao Novo DEIT-Libras (2013). Assim, ressaltamos sinais em Libras representados unicamente pelo recurso da datilologia, processo que equivale à representação na Libras por letras do alfabeto da LP. Por serem os empréstimos muitas das vezes momentâneos, os sinais indicados nesta pesquisa ou em outros objetos de registro da Libras, podem ser substituídos por sinais, construções próprias da língua, sendo de responsabilidade dos pesquisadores estarem atentos às modificações.

\section{REFERÊNCIAS}

ALVES, leda Maria. Neologismo: criação lexical. São Paulo: Ática, 2007.

BARROS, Mariângela Estelita. ELiS: sistema brasileiro de escrita das línguas de sinais. Porto Alegre: Penso, 2015.

BASÍLIO, Margarida. Formação e classe de palavras no português do brasil. São Paulo: Contexto, 2004.

BATTISON, Robbin M. Lexical borrowing in American Sign Language. SilverSpring, 1978. 


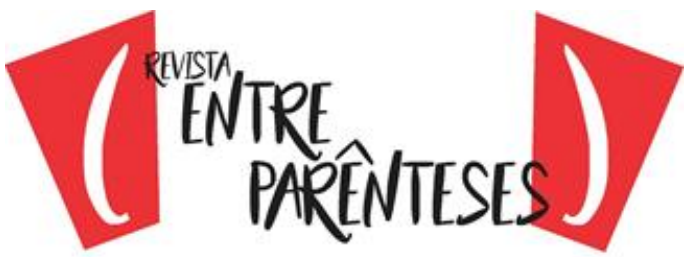

BELLUGI, U.; NEWKIRK, D. Formal devices for creating new sign in American Sign Language. In Sign Language Research, vol 30, W.D.C.: Gallaudet University, Spring, 1981.

BIDERMAN, Maria Tereza Camargo. Teoria linguística. São Paulo: Editora Martins Fontes, 2001.

BRASIL. 2002. Lei oㅜ 10.436 de 24 de abril de 2002. Brasília. Presidência da República, Casa Civil, Subchefia para Assuntos Jurídicos. Dispõe sobre a Língua Brasileira de Sinais - Libras e dá outras providências. Disponível:

emhttp://www.planalto.presidencia.gov.br/CCIVIL/LEIS/2002/L10436.htm. Acesso em 15 de ago de 2018.

BRASIL. 2005. Decreto o 5626 de 22 de dezembro de 2005. Brasília, Presidência da República, Casa Civil, Subchefia para assuntos Jurídicos. Regulamenta a Língua Brasileira de Sinais. Disponível em: http://www.presidencia.gov.br/ccivil/_Ato2004-2006/2005/Decreto/D5626.htm. Acesso em: 15 de ago de 2018.

CAPOVILLA, F. C.; RAPHAEL, W. D.; MAURICIO, A. C. L. Novo DEIT-Libras: dicionário enciclopédico ilustrado trilíngue da língua de sinais brasileira. $3^{\underline{a}}$ ed. São Paulo: Edusp, 2013. 2 v.

CARVALHO, Nelly. Empréstimos linguísticos. São Paulo: Ática, 1989. Dicionário de termos linguísticos. Disponível em: $<$ http://www.ait.pt/recursos/dic_term_ling/index2.htm>. Acesso em: 20 de ago de 2018.

BRITO, L. F. et al. Por uma gramática de língua de sinais. Rio de Janeiro: Tempo Brasileiro / UFRJ, depto. Linguística e Filosofia, 1995.

GARCEZ, P. M.; ZILLES, A. M. S. Estrangeirismos: desejos e ameaças. In: FARACO, Carlos Alberto. (Org). Estrangeirismos: guerras em torno da língua. 2 ed. São Paulo, 2002, p.15-36.

MINEIRO, A. et al. Aspectos da Polissemia Nominal em Língua Gestual Portuguesa. In: Revista Polissema, vol. 8, p. 40-64. Porto/Portugal, 2008.

NASCIMENTO, Sandra Patrícia Faria do. Representações lexicais da língua de sinais brasileira: uma proposta lexicográfica. 2009. $325 \mathrm{f}$. Tese (Doutorado em Linguística) - Universidade Federal de Brasília - UNB: Brasília, 2009. 


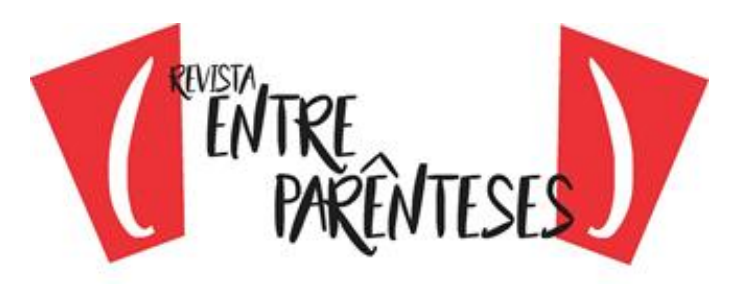

NASCIMENTO, Cristiane Batista do. Empréstimo linguístico do português na Língua de Sinais Brasileira - LSB: línguas em contato. 2010. 111 f. Dissertação (Mestrado em Linguística) - Universidade de Brasília - UNB: Brasília, 2010.

QUADROS, Ronice Muller de; KARNOPP, Lodenir Becker. Língua de sinais brasileira: estudos linguísticos. Porto Alegre: Artes Médicas, 2004.

; PIMENTA, N. Curso de Libras 1. Rio de Janeiro: LSB Vídeo. 2006.

SUTTON-SPENCE, R; WOLL, B. The lingustics of British sign Language: an introduction. Cambridge: University Press, 1999.

TIMBANE, Alexandre António. Os estrangeirismos e os empréstimos no português falado em Moçambique. Caderno de estudos linguísticos. v. 54, n. 2, p. 289-304. Araraquara, 2012.

Recebido em 29/09/2018.

Aceito em 03/12/2018. 